\title{
Persistent Expression of Fas/FasL mRNA in the Mouse Hippocampus After a Single NMDA Injection
}

\author{
*Song-Woo Shin, *†Jong-Wook Park, ††Min-Ho Suh, †Sung-Il Suh, and *Byung-Kil Choe \\ Departments of $\nmid$ Immunology and $\ddagger$ Microbiology, School of Medicine, and *Institute of Medical Science, \\ Keimyung University, Taegu, Korea
}

\begin{abstract}
Synaptic reorganization plays a very important role in brain adaptations to environmental stimuli, diseases, and aging processes. The NMDA model of excitotoxic injury was used to investigate the long-term molecular changes in the surviving neural cells in the mouse hippocampus. We demonstrated that a single intraperitoneal injection of NMDA produces persistent expression of c-fos, c-jun, Fas, and Fas ligand (Fas $L$ ) mRNA in the hippocampus for 5 months. To determine the cellular origin of those gene transcripts in our in vivo model, a glial cell line and primary fetal neuronal culture were used to investigate the inducibility of the c-fos, c-jun, Fas, and Fas $L$ mRNA by NMDA. Both c-fos and Fas mRNA expression was observed in the NMDA-treated glial or neuronal cultures; however, c-jun and FasL mRNA was undetectable in this study. In our in vivo model, mossy fiber sprouting and apoptosis were also observed up to 40 days after the NMDA injection. Therefore, we hypothesize that the observed long-term expression of c-fos, c-jun, Fas, and Fas $L$ mRNAs may reflect the ongoing synaptic reorganization. Key Words: NMDA-Long-term gene expression-Hippocampus.

J. Neurochem. 71, 1773-1776 (1998).
\end{abstract}

Most excitotoxins are structural analogues of glutamate that bind to one of the ionotropic glutamate receptors: the NMDA receptor or the $\alpha$-amino-3-hydroxy-5-methylisoxazole-4-propionate (AMPA)/kainate receptor. Binding triggers massive influx of calcium, which is fatal to neurons (Meldrum and Garthwaite, 1990). Synaptic activation of glutamate receptors exerts a broad spectrum of effects on physiological and pathological processes in the CNS (Vendrell et al., 1993). Systemically applied kainate is known to induce seizure behavior in rats within $90 \mathrm{~min}$ followed by death of hilar and pyramidal neurons of the CA1 and CA3 in the hippocampus within 3 days, and this has been called as longterm, selective neurodegeneration (Dragunow and Preston, 1995). However, kainate is known to induce very long-term expression of AP-1 transcription factor (Pennypacker, 1997) and enkephalins (Bing et al., 1997).

We have reported that a single systemic application of a convulsive dose of NMDA to mice results in both short- and long-term effects on the CNS (Y. Jung et al., submitted). Manifestations of acute injury subsided within 3 days, and then delayed neuronal degeneration began to appear at the hippocampus around 10 days after injection and lasted as long as 30 days. The long-term effect of NMDA excitotoxi- city, especially on the immediate-early genes c-fos/c-jun and the apoptosis-related genes $F$ as/Fas ligand (FasL), has never been investigated previously. Therefore, we have decided to extend our investigations to demonstrate that NMDA leads to the up-regulation of c-fos, c-jun, Fas, and FasL mRNA in the mouse hippocampus for up to 5 months and probably even longer.

\section{MATERIALS AND METHODS}

\section{Animals and treatments}

Groups of ICR mice maintained at the DongSan Medical Center were injected with $70 \mathrm{mg} / \mathrm{kg}$ (i.p.) NMDA (Sigma, U.S.A.) prepared in phosphate-buffered saline ( $\mathrm{pH} 7.4$ ) and killed at 1, 4, 10, 30, 60, and 150 days following treatments. The mice were anesthetized by injecting with Entobar and perfused with phosphate-buffered saline containing 2 units/ $\mathrm{ml}$ heparin through the heart. Then the whole brain was removed to prepare for the molecular biological and histological investigations. Animal experimentation protocols were approved by the Keimyung University Committee on the Animal Care and Experimentation at the DongSan Medical Center.

\section{Molecular biological methods}

For the general molecular biological techniques such as nucleic acid extraction, RT, PCR, cloning, and DNA sequencing, methodologies described by Ausubel et al. (1992) were followed.

\section{Cell biological methods}

The neurite outgrowth was demonstrated by the Timm's silver method (Sloviter, 1982). The apoptotic cells were examined by the TdT-mediated dUTP-biotin nick end-labeling (TUNEL) method described by Gavrieli et al. (1992).

Resubmitted manuscript received June 30, 1998; accepted June 30, 1998.

Address correspondence and reprint requests to Dr. B.-K. Choe at Institute for Medical Science, Keimyung University, 194 DongSan Dong, Taegu, 700-712, Korea.

Abbreviations used: FasL, Fas ligand; G3PDH, glyceraldehyde 3-phosphate dehydrogenase. 
TABLE 1. Primers used for PCR amplifications

\begin{tabular}{ll}
\hline \multicolumn{1}{c}{ Primer $^{a}$} & \multicolumn{1}{c}{ Sequence } \\
\hline G3PDH-S & GCCACCCAGAAGACTGTGGATGGC \\
G3PDH-AS & CATGTAGGCCATGAGGTCCACCAC \\
Fas-S & TCACTCCAGACATTGTCCTTCATT \\
Fas-AS & AGGAGGGCAAGATAGATGAGATC \\
FasL-S & TTAAAGCTTATACAAGCCGAAAAGGTC \\
FasL-AS & CAGTCTTGCAACAACCAGCCCC \\
c-jun-S & GGCTGAACTGCATAGCCAGAACACGC \\
c-jun-AS & GGCGGCAATGCGGTTCCTCATGCGC \\
c-fos-S & GGGCTCTCCTGTCAACACACAGGAC \\
c-fos-AS & GATCTGTCTCCGCTTGGAGTGTATCTG \\
\hline
\end{tabular}

${ }^{a}$ AS, antisense; S, sense.

\section{PCR primers}

Eight oligonucleotides were designed according to the sequences of previously reported glyceraldehyde-3-phosphate dehydrogenase (G3PDH) (Sabath et al., 1990), Fas (Watanabe et al., 1992), FasL (Takahashi et al., 1994), c-fos (Van Beveren et al., 1983), and c-jun (Lamph et al., 1988) cDNA as described in Table 1.

\section{In situ RT-PCR}

The general methodology has been described by Nuovo (1992); however, details of the method such as tissue preparation, slide preparation, and the cycling condition were modified in our laboratory. In brief, mouse brain was frozen and sectioned at a thickness of $10 \mu \mathrm{m}$. Sections were mounted onto a 3-aminopropyltriethoxysilane (Sigma, U.S.A.)-coated slide. Sections were fixed in $4 \%$ paraformaldehyde, washed with phosphate-buffered saline, and dehydrated with serial concentrations of ethanol. Sections were then treated with RNase-free DNase (Promega, U.S.A.) using $8 \mathrm{U} / 100 \mu \mathrm{l}$ for $3 \mathrm{~h}$ at $37^{\circ} \mathrm{C}$ and heated to $94^{\circ} \mathrm{C}$ for $5 \mathrm{~min}$. cDNA was generated using M-MuLV reverse transcriptase (Promega) and amplified using Taq DNA polymerase (Promega) and PCR digoxigenin labeling mix (Boehringer Mannheim, Germany). Slide seal for in situ PCR (TaKaRa Japan) was located around the tissue section on the slide and covered with PCR mixture. PCR amplification (30 cycles) was carried out at $94^{\circ} \mathrm{C}$ for $30 \mathrm{~s}, 65^{\circ} \mathrm{C}$ for $30 \mathrm{~s}$, and $72^{\circ} \mathrm{C}$ for $30 \mathrm{~s}$ in a HYBAID thermocycler (OmniGene, U.S.A.). Amplified cDNA was detected with the digoxigenin DNAlabeling and detection kit (Boehringer Mannheim).

\section{Cell cultures and treatments}

For the cultivation of primary neuronal cells from fetal rat brain, methodologies by Brewer et al. (1993) were adopted. Primary cultures of cortical and hippocampal neurons were prepared from 15-day-old fetal rat (Sprague-Dawley) on poly-L-lysine $(25 \mu \mathrm{g} / \mathrm{ml})$-coated 35 -mm-diameter dishes in $2 \mathrm{ml}$ at a density of $3 \times 10^{6} \mathrm{cells} / \mathrm{ml}$ and maintained in a Neurobasal medium (GibcoBRL, U.S.A.) supplemented with $2 \% \mathrm{~B} 27,500 \mu M$ L-glutamine, $25 \mu M$ glutamate, and 25 $\mu M$ 2-mercaptoethanol. C6 glioma cells were cultured in Dulbecco's modified Eagle's medium (GibcoBRL) supplemented with $10 \%$ heat-inactivated fetal calf serum. From day $5,10,30,100,300$, and 1,000 $\mu M$ NMDA was added to each culture. After a 3-h incubation in NMDA and a 1day incubation in fresh medium, total RNA was purified with RNAzol B (BIOTEX, U.S.A.). First-strand cDNA was generated by incubating $1 \mu \mathrm{g}$ of total RNA with M-MuLV reverse transcriptase. PCR amplification was carried out at $94^{\circ} \mathrm{C}$ for $30 \mathrm{~s}, 65^{\circ} \mathrm{C}$ for $30 \mathrm{~s}$, and $72^{\circ} \mathrm{C}$ for $30 \mathrm{~s}$. PCR products were also subcloned into pT7Blue $\mathrm{T}$-vector (Novagen, U.S.A.) and sequenced by a primer extension method.

\section{RESULTS AND DISCUSSION}

It has been previously shown that the expression of a few genes, including $F a s$ and tumor necrosis factor- $\alpha$, increased in the mouse hippocamus after NMDA excitotoxic injury (Y. Jung et al., submitted). We have now examined the longterm expression of c-fos, c-jun, Fas, and FasL in this study. Their expression persisted in the mouse hippocamus for 150 days, the longest time point studied after NMDA injection (Figs. 1 and 2).

The mRNAs for c-fos, c-jun, Fas, and FasL are undetectable in most of the brain without NMDA treatment, and these mRNAs become detectable in the hippocampus $\sim 10$ days after the NMDA injection. To determine the expression of other gene transcripts for comparison, other sections were processed. These other genes included cyclic AMP response element-binding protein, NMDA receptor subunit 1, growthassociated protein-43, and tumor necrosis factor- $\alpha$. However, enhanced expression of these mRNAs in the hippocampus and mossy fiber sprouting lasted up to $\sim 40$ days (authors' unpublished data), whereas c-fos/c-jun and Fas/FasL mRNA lasted for 150 days.

The most interesting finding from this study was the unexpected prolonged expression of c-fos/c-jun and Fas/FasL gene transcripts in the hippocamus after a single injection of NMDA. Both NMDA and kainate generate free radicals and reactive oxygen species. It has been emphasized that those reactive oxygen species induce neuronal apoptosis $(\mathrm{Pa}-$ tel et al., 1996). Therefore, the notion that neural apoptosis
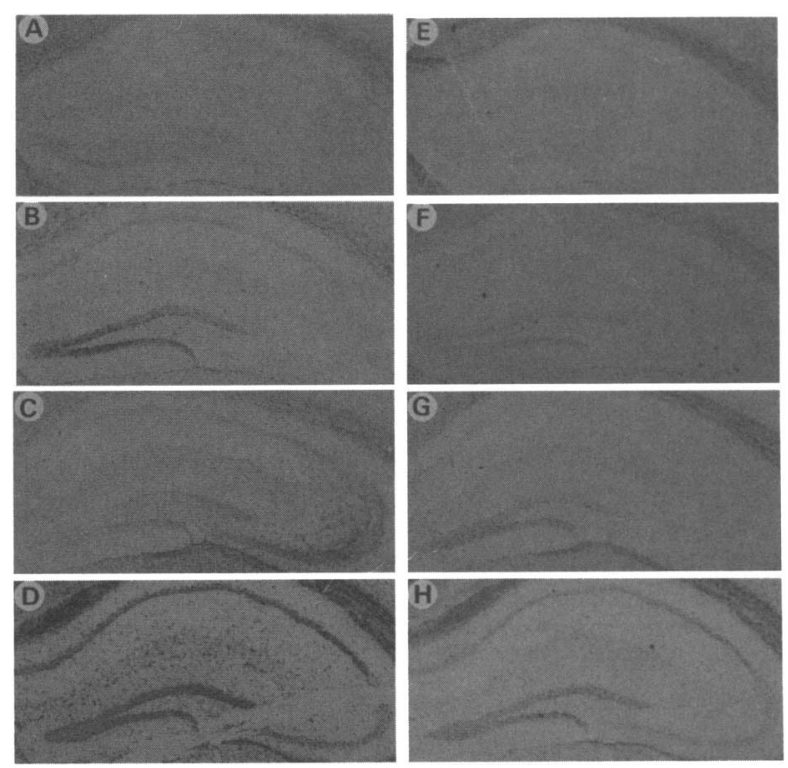

FIG. 1. Representative photomicrographs from three separate assays of (A-D) c-fos and (E-H) c-jun mRNA expression in the mouse hippocampus. The sections are from control animals $(A$ and $E$ ) and animals 30 (B and $F$ ), 90 (C and G), and 150 (D and $\mathrm{H})$ days after NMDA treatment. Note the long-lasting changes in the intensity of the image of the transcripts. 

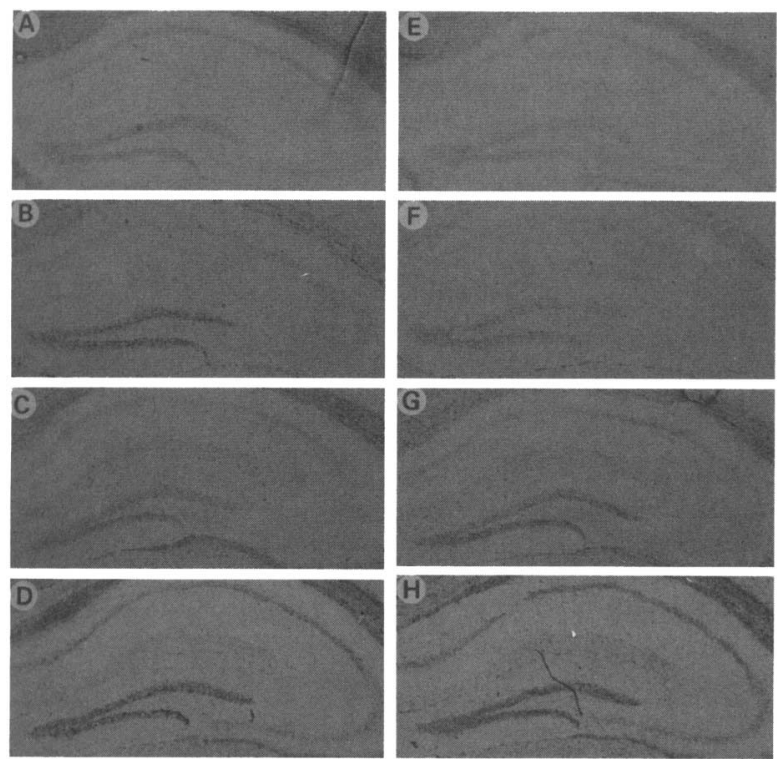

FIG. 2. Expression of Fas/FasL mRNA in the mouse hippocampus after NMDA treatment. Representative photomicrographs from three separate experiments are shown: (A-D) Fas mRNA and $(E-H)$ FasL mRNA. The sections are from control animals ( $A$ and $E$ ) and animals 30 (B and $F$ ), 90 (C and G), and 150 (D and $H$ ) days after NMDA treatment.

might be also regulated by specific apoptosis-related genes in the CNS has never been entertained except by one report by Matsuyama et al. (1995). They reported an acute induction of Fas mRNA expression in the postischemic mouse forebrain.

Fas and FasL belong to a family of cell surface proteins that include tumor necrosis factor- $\alpha$ and nerve growth factor (NGF) receptor, all of which mediate apoptosis. The Fas/FasL pathway is one of the major apoptotic mechanisms of immune cells (Nagata, 1997). Mechanisms of Fas/FasL gene expression in the CNS are not elucidated yet.

Concerning c-fos gene expression, there have been some suggestions that this gene may be producing long-. term structural and functional changes in the stimulated neuron through unknown complex regulatory mechanisms (Bing et al., 1997; Pennypacker, 1997). Several reports (Smeyne et al., 1993; Preston et al., 1996) have implicated the $c$-fos gene in the induction of apoptosis. The results presented in Fig. 1 suggested that $\mathrm{c}$-fos could be part of a chain of molecular events that culminate in occasional activation of the Fas/FasL gene in extraordinarily overactivated neurons.

To determine the neural origins of c-fos, c-jun, Fas, and FasL mRNA, total RNAs were prepared from mouse hippocampus, and the occurrence of those transcripts was confirmed by RT-PCR (Fig. 3). The authenticity of those amplified cDNA was verified by DNA sequence analysis (data not shown). Furthermore, to identify the cellular origin of those gene transcripts, rat cortical neuronal culture and rat $\mathrm{C} 6$ glioma cell culture were used. As shown in Fig. 3, c-fos gene expression was inducible in both neuronal and glia cell cultures by NMDA. Fas gene expression was also inducible in both neuronal and glia cell cultures. However, regardless of the wide-range coverage of the concentration, NMDA treatment did not induce expression of c-jun and FasL transcripts in both neuronal and glioma cultures in this experiment, the reasons for which are unclear at present. However, recently three groups reported the expression of FasL mRNA by glioblastoma cell lines and primary astrocytomas (Gratas et al., 1997; Saas et al., 1997; Weller et al., 1997). Expression of FasL mRNA in the CNS may be regulated tightly by unknown mechanisms. Therefore, the possibility of Fas/FasL involvement in neural cell apoptosis remains open.

Brace et al. (1993) have shown that both NMDA and kainate damage not only neurons but also myelin and compromise even the integrity of the blood-brain barrier. Recovery of the blood-brain barrier appeared to take place over 12 days, whereas remyelination occurs over a period of 3 months. Therefore, it is possible that the long-term expression of c-fos/c-jun and Fas/FasL mRNA in the hippocampus in our study may reflect synaptic reorganization. Neurite remodeling involves extensive synaptic relocalization and reassembly of receptors. It is noteworthy that long-term alteration in neuronal activity itself can also produce a long-lasting reorganization of synaptic connections in the mammalian CNS (Sutula et al., 1988; BenAri and Represa, 1990; Magarinos et al., 1997) and confer functional alterations such as a long-lasting increase in seizure susceptibility to the animal (Bing et al., 1997). In conclusion, each neuronal insult and recovery appears to

$\begin{array}{llllllllllll}M & 1 & 2 & 3 & 4 & 5 & 6 & 7 & 8 & 9 & 10 & 11\end{array}$

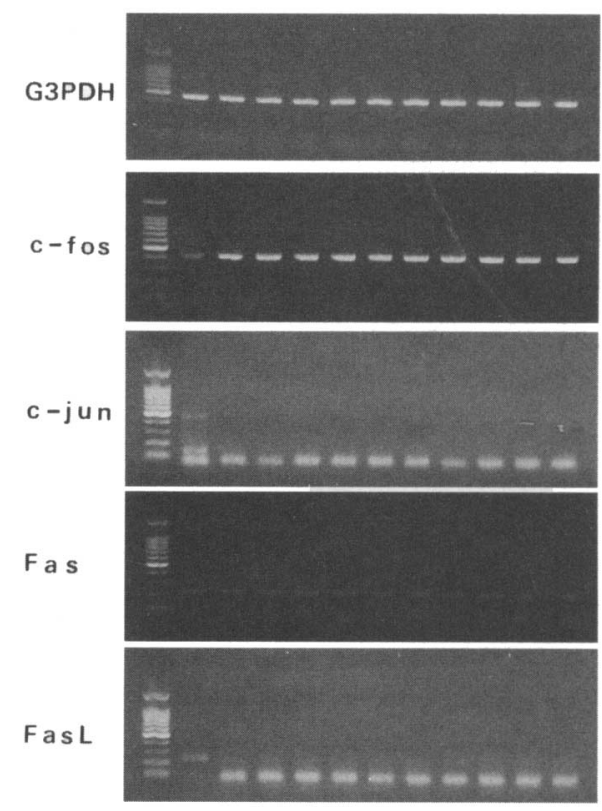

FIG. 3. Demonstration of c-fos, c-jun, Fas, and FasL cDNAs from NMDA-treated mouse brain, rat fetal neuronal culture, and C6 glioma culture. Total RNAs isolated from NMDA-treated mouse brain and cell cultures were reverse-transcribed and amplified by PCR each using proper primers: lane 1, brain; lanes $2-6$, neuronal culture $(10,30,100,300$, and $1,000 \mu M$ NMDA, respectively); and lanes $7-11$, C6 glioma culture $(10,30,100$, $300,1,000 \mu M$ NMDA, respectively). Lane $\mathrm{M}$, molecular weight ladder. 
introduce long-lasting molecular, structural, and functional changes to the neuron, including an occasional accidental activation of apoptosis-related genes.

Acknowledgment: This work was supported by grant HMP-96-M-2-008 from the Ministry of Health and Welfare, Republic of Korea (to B.-K.C.).

\section{REFERENCES}

Ausubel F. M., Brent R., Kingston R. E., Moore D. D., Seidman J. G., Smith J. A., and Struhl K. (1992) Short Protocols in Molecular Biology, 2nd edit. John Wiley \& Sons, New York.

Ben-Ari Y. and Represa A. (1990) Brief seizure episodes induce long-term potentiation and mossy fiber sprouting in the hippocampus. Trends Neurosci. 13, 312-318.

Bing G., Wilson B., Hudson P., Jin L., Feng Z., Zhang W., Bing R., and Hong J. S. (1997) A single dose of kainic acid elevates the levels of enkephalins and activator protein- 1 transcription factors in the hippocampus for up to 1 year. Proc. Natl. Acad. Sci. USA 94, 9422-9427.

Brace H., Latimer M., and Winn P. (1993) Neurotoxicity, bloodbrain barrier breakdown, demyelination and remyelination associated with NMDA-induced lesions of the rat lateral hypothalamus. Brain Res. Bull. 43, 447-455.

Brewer G. J., Torricelli J. R., Evege E. K., and Price P. J. (1993) Optimized survival of hippocampal neurons in B27-supplemented Neurobasal, a new serum-free medium combination. $J$. Neurosci. Res. 35, 567-576.

Dragunow M. and Preston K. (1995) The role of inducible transcription factors in apoptotic nerve cell death. Brain Res. Rev. 21, $1-28$.

Gavrieli Y., Sherman Y., and Ben-Sasson S. A. (1992) Identification of programmed cell death in situ via specific labelling of nuclear DNA fragmentation. J. Cell Biol. 119, 493-501.

Gratas C., Tohma Y., Van Meir E. G., Klein M., Tenan M., Ishii N., Tachibana O., Kleihues P., and Ohgaki H. (1997) Fas ligand expression in glioblastoma cell lines and primary astrocytic brain tumors. Brain Pathol. 7, 863-869.

Lamph W. W., Wamsley P., Sassone-Corsi P., and Verma I. M. (1988) Induction of proto-oncogene JUN/AP-1 by serum and TPA. Nature 334, 629-631.

Magarinos A. M., Verdugo J. M. G., and McEwen B. S. (1997) Chronic stress alters synaptic terminal structure in hippocampus. Proc. Natl. Acad. Sci. USA 94, 14002-14008.

Matsuyama T., Hata R., Yamamoto Y., Tagaya M., Akita H., Uno H., Wanaka A., Furuyama J., and Sugita M. (1995) Localization of Fas antigen mRNA induced in postischemic murine forebrain by in situ hybridization. Mol. Brain Res. 34, 166-172.

Meldrum B. and Garthwaite J. (1990) Excitatory amino acid neuro- toxicity and neurodegenerative disease. Trends Pharmacol. Sci. 11, 379-387.

Nagata S. (1997) Apoptosis by death factor. Cell 88, 355-365.

Nuovo G. J. (1992) PCR In Situ Hybridization. Raven Press, New York.

Patel M., Day B. J., Crapo J. D., Fridovich I., and McNamara J. O. (1996) Requirement for superoxide in excitotoxic cell death. Neuron 16, 345-355.

Pennypacker K. (1997) Transcription factors in brain injury. Histol. Histopathol. 12, 1125-1133.

Preston G. A., Lyon T. T., Yin Y., Lang J. E., Solomon G., Annab L., Srinivasan D. G., Alcorta D. A., and Barrett J. C. (1996) Induction of apoptosis by c-fos protein. Mol. Cell. Biol. 16, $211-218$.

Saas P., Walker P. R., Hahne M., Quiquerez A. L., Schnuriger V., Perrin G., French L., Van Meir E. G., de Tribolet N., Tschopp J., and Dietrich P. Y. (1997) Fas ligand expression by astrocytoma in vivo: maintaining immune privilege in the brain? $J$. Clin. Invest. 99, 1173-1178.

Sabath D. E., Broome H. E., and Prystowsky M. B. (1990) Glyceraldehyde-3-phosphate dehydrogenase mRNA is a major interleukin 2 -induced transcript in a cloned T-helper lymphocyte. Gene 91, $185-191$.

Sloviter R. S. (1982) A simplified TIMM stain procedure compatible with formaldehyde fixation and routine paraffin embedding of rat brain. Brain Res. Bull. 8, 771-774.

Smeyne R. J., Vendree M., Hayward M., Baker S., Miao G., Schilling K., Robertson L., Curran T., and Morgan J. (1993) Continuous $\mathrm{c}$-fos expression precedes programmed cell death in vivo. Nature 363, 166-169.

Sutula T. P., He X. X., and Scott G. (1988) Synaptic reorganization in the hippocampus induced by abnormal functional activity. Science 239, 1147-1150.

Takahashi T., Tanaka M., Brannan C. I., Jenkins N. A., Copeland N. G., Suda T., and Nagata S. (1994) Generalized lymphoproliferation disease (gld) in mice caused by a point mutation in the Fas ligand. Cell 76, 969-976.

Van Beveren C., Van Straaten F., Curran T., Muller R., and Verma I. M. (1983) Analysis of FBJ-MuSV provirus and c-fos (mouse) gene reveals that viral and cellular fos gene products have different carboxy termini. Cell 32, 1241-1255.

Vendrell M., Curran T., and Morgan J. I. (1993) Glutamate, immediate-early genes and cell death in the nervous system. Ann. NY Acad. Sci. 679, 132-141.

Watanabe F. R., Brannan C. I., Itoh N., Yonehara S., Copeland N. G., Jenkins N. A., and Nagata S. (1992) The cDNA structure, expression, and chromosomal assignment of the mouse Fas antigen. J. Immunol. 148, 1274-1297.

Weller M., Weinstock C., Will C., Wagenknecht B., Dichgans J., Lang F., and Gulbins E. (1997) CD95-dependent T cell killing by glioma cells expressing CD95 ligand: more on tumor immune escape, the CD95 counterattack, and the immune privilege of the brain. Cell. Physiol. Biochem. 7, 282-288. 